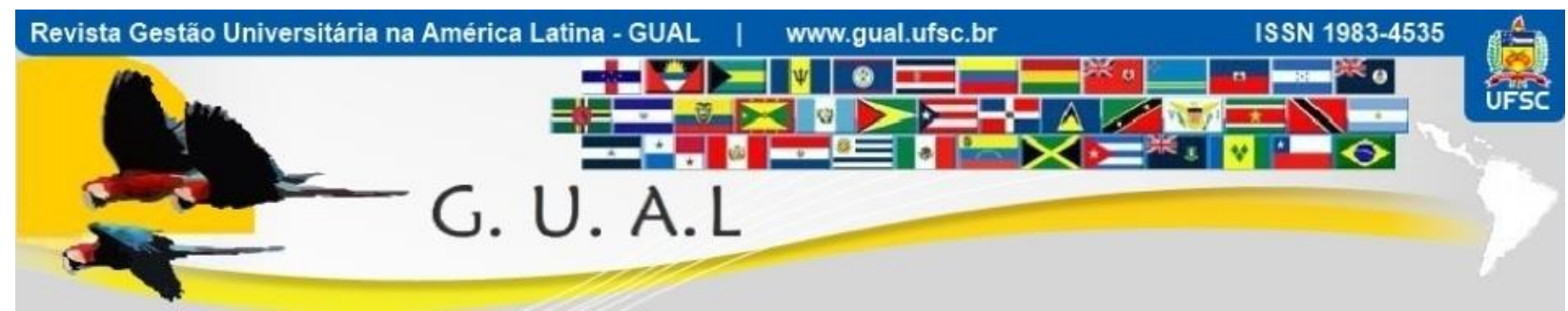

DOI: http://dx.doi.org/10.5007/1983-4535.2014v7n3p77

\title{
CONTRIBUIÇÃO DO PLANO DE DESENVOLVIMENTO INSTITUCIONAL COMO FERRAMENTA DE PLANEJAMENTO ESTRATÉGICO NA GESTÃO DE UMA INSTITUIÇÃO PRIVADA DE ENSINO SUPERIOR DO RECIFE
}

\author{
CONTRIBUTION OF INSTITUTIONAL DEVELOPMENT PLAN AS A TOOL FOR \\ STRATEGIC PLANNING IN THE MANAGEMENT OF A PRIVATE HIGHER \\ EDUCATION INSTITUTION FROM RECIFE
}

Maria Caroline Carneiro Silva, Mestranda Universidade Federal de Pernambuco - UFPE mariacarolinec@yahoo.com.br

Jéssica Maria Muniz Côrtes, Mestranda Universidade Federal de Pernambuco - UFPE jmmcortes8@gmail.com

Joséte Florêncio dos Santos, Doutora Universidade Federal de Pernambuco - UFPE jfs@ufpe.br

Maria de Lourdes de Azevedo Barbosa, Doutora Universidade Federal de Pernambuco - UFPE lourdesbarbosa@gmail.com

Recebido em 19/fevereiro/2013

Aprovado em 26/maio/2014

Sistema de Avaliação: Double Blind Review

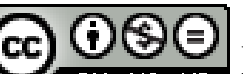

Esta obra está sob uma Licença Creative Commons Atribuição-Uso. 


\title{
RESUMO
}

Esta pesquisa analisou as contribuições do Plano de Desenvolvimento Institucional como ferramenta de planejamento estratégico na gestão de uma instituição privada de ensino superior do Recife. O tópico selecionado é uma replicação da dissertação de Silva (2013), "Contribuições do Plano De Desenvolvimento Institucional e do Planejamento Estratégico na Gestão de Universidades Federais Brasileiras". Para isto, foi realizado um estudo de caso qualitativo e utilizou métodos como codificação, redação de memorandos, amostragem teórica para analisar o resultado, conforme orientado por Charmaz (2009), buscando criar categorias sólidas e análises reveladoras através da saturação e classificação. O estudo corroborou com outros estudos sobre o tema. Foi observado que a instituição utilizou o PDI como ferramenta estratégica, que enfrentou resistência na implantação, porém o saldo foi positivo para instituição visto que contribuiu para a comunicação interna que era algo desejado pela instituição.

Palavras-chave: PDI. Planejamento Estratégico. IES. Estudo de Caso.

\begin{abstract}
This study examined the contributions of the Institutional Development Plan as a strategic planning tool in the management of a private institution of higher education in Recife. The selected topic is a replication of the Silva's dissertation (2013), "Contributions of the Institutional Development Plan and Strategic Planning to the Management of Brazilian Federal Universities". Thus, a qualitative case study was conducted and methods such as coding, writing memos, theoretical sampling to analyze the results were used as directed by Charmaz (2009), seeking to create solid categories and revealing analysis by saturating and classification. The study has corroborated with other studies on the subject . It was observed that the institution used the IDP as a strategic tool, which faced resistance in implementation, but the balance of the use of the IDP as a strategic planning tool was positive for the institution.
\end{abstract}

Keywords : IDP. Strategic Planning. IES. Case Study. 


\section{CONTRIBUICÃO DO PLANO DE DESENVOLVIMENTO INSTITUCIONAL COMO FERRAMENTA DE \\ PLANEJAMENTO ESTRATÉGICO NA GESTÃO DE UMA INSTITUIÇÃO PRIVADA DE ENSINO \\ SUPERIOR DO RECIFE \\ DOI: http://dx.doi.org/10.5007/1983-4535.2014v7n3p77}

\section{INTRODUÇÃO}

Segundo Moritz et al (2012), a universidade deixa de ser para poucos e passa a atingir muitos, a universidade virou um centro de oportunidades, além de todos os seus objetivos já propostos. Logo, daqui por diante suas ações terão que ser voltadas para o futuro, não importa a natureza da instituição.

Com o objetivo de auxiliar as instituições de ensino superior a se prepararem para o futuro, o Decreto n. 5.773, de 9 de maio de 2006, que dispõe sobre o exercício das funções de regulação, supervisão e avaliação de instituições de educação superior e cursos superiores de graduação e sequenciais no sistema federal de ensino, passou a exigir uma nova adequação dos procedimentos de elaboração e análise do Plano de Desenvolvimento Institucional - PDI (MEC, 2013).

O Plano de Desenvolvimento Institucional, elaborado para um período de 5 (cinco) anos, é o documento que identifica a Instituição de Ensino Superior (IES) e sua elaboração deverá explicitar o modo pelo qual o documento foi construído e a interferência que exercerá sobre a dinâmica da Instituição. O PDI tem como pressuposto o atendimento ao conjunto de normas vigentes, no que diz respeito à sua filosofia de trabalho, à missão a que se propõe a instituição, às diretrizes pedagógicas que orientam suas ações, à sua estrutura organizacional e às atividades acadêmicas que desenvolve e/ou que pretende desenvolver.

Outra característica do PDI é a coesão interna entre setores e atividades, a forma como se inter-relacionam. Silva (2013) referindo-se a Cardoso (2006) diz que o PDI deve servir para toda a instituição, buscando a integração dos diversos setores organizacionais, das dimensões e dos níveis de planejamento (estratégico, tático e operacional).

É interessante destacar que o PDI possui algumas características que são encontradas também no planejamento estratégico, como a missão da instituição, apesar dessas características não serem suficientes para caracterizar o PDI como estratégico. Entretanto, contribui e serve de estímulo para que as instituições de educação superior avancem para torná-lo um planejamento estratégico (SILVA, 2013).

Tendo em vista a importância do planejamento estratégico e do PDI para o desenvolvimento das Instituições de Ensino Superior, este trabalho se propõe a analisar a contribuição do Plano de Desenvolvimento Institucional como ferramenta de planejamento estratégico na gestão de uma Faculdade do Recife por meio de uma replicação da dissertação 
de Silva (2013), “CONTRIBUIÇÕES DO PLANO DE DESENVOLVIMENTO INSTITUCIONAL E DO PLANEJAMENTO ESTRATÉGICO NA GESTÃO DE UNIVERSIDADES FEDERAIS BRASILEIRAS”. A partir disso, esta pesquisa buscou conhecer a percepção do gestor de uma IES da cidade do Recife sobre o planejamento estratégico e o PDI, e apontar suas contribuições para o planejamento estratégico na gestão dessa Instituição.

\subsection{PERGUNTA DE PESQUISA}

O problema de pesquisa, segundo Merriam (2009), visa desafiar a mente e responder o que se quer saber, explorar ou examinar. Uma pergunta específica é o reconhecimento de uma lacuna no conhecimento. Desta maneira, a pergunta de pesquisa deste estudo de caso é: De que forma o Plano de Desenvolvimento Institucional como ferramenta de planejamento estratégico contribui com a gestão de uma Instituição do Ensino Superior do Recife?

\section{REVISÃO DE LITERATURA}

\subsection{AS IES NO BRASIL}

Na economia do conhecimento a busca é pela educação continuada e pela atualização constante do conhecimento. A Educação Superior vem dando oportunidade aos acadêmicos de buscar, produzir e divulgar o saber, a ciência e a tecnologia em todas as áreas com a função de preparar profissionais integrados com a realidade e atentos às demandas do mercado. Este aumento pela demanda por profissionais qualificados provocou um crescimento da oferta do segmento de educação superior, de modo particular das faculdades privadas, que contribuíram fortemente para a ampliação do número de vagas oferecidas e, com isto, facilitou o acesso à educação continuada pelas diversas classes sociais, além de contribuir para a interiorização do ensino.

Apesar disso, houve uma redução no número de Instituições Privadas de Ensino Superior no Nordeste, segundo os dados divulgados pelo INEP (2013). Em 2009 havia 2.069 instituições privadas de ensino superior no Brasil, destas 387 estavam instaladas no Nordeste e 74 no estado de Pernambuco. Já em 2011, o número nacional aumentou para 2.100, no entanto caiu para 369 no Nordeste e 67 em Pernambuco. Essa contração no número de Instituições Privadas de Ensino Superior no Nordeste, pode ter sido ocasionado pelo fato de 


\section{CONTRIBUICÃO DO PLANO DE DESENVOLVIMENTO INSTITUCIONAL COMO FERRAMENTA DE \\ PLANEJAMENTO ESTRATÉGICO NA GESTÃO DE UMA INSTITUIÇÃO PRIVADA DE ENSINO \\ SUPERIOR DO RECIFE \\ DOI: http://dx.doi.org/10.5007/1983-4535.2014v7n3p77}

ser um segmento que requer grandes investimentos por parte das empresas e do governo devido à função e a importância de preparar profissionais em concordância com a realidade e atentos às demandas do mercado e das comunidades locais.

Além destes obstáculos, as instituições enfrentam outros impedimentos, como a dificuldade em ocupar todas as vagas oferecidas pelo vestibular, a falta de relacionamento com os alunos, a falta de medição de desempenho com critérios mais objetivos, a falta de perspectivas claras de futuro, a distância do mercado empregador, a distância da comunidade em que está inserida e a insatisfação interna (MACHADO, 2008 apud SILVA, 2013). Logo, como algo necessário à sobrevivência das instituições, ao cumprimento das exigências de um mercado competitivo e da legislação surge a necessidade de criação e utilização do planejamento estratégico como ferramenta administrativa e de gestão visando minimizar esses impactos e auxiliando nas tomadas de decisões.

\subsection{PLANEJAMENTO ESTRATÉGICO E PDI}

De acordo com a perspectiva de Rissi et al (2009), o planejamento estratégico nas universidades é o Plano de Desenvolvimento Institucional (PDI). Apesar disso, a LDB, a Lei do SINAES, o decreto presidencial que regulamenta o SINAES e a própria orientação do MEC (BRASIL, 1996; 2004; 2006; 2007) para a elaboração do PDI, não faz referências à estratégia ou planejamento estratégico, além disso, o PDI não possui a maioria dos itens para compor um planejamento estratégico corroborando com os estudos de Kich et al (2010), Oliveira (2008), Almeida (2010), Kluyver e Pearce II (2010), Mintzberg, Ahlstrand e Lampel (2010) e Pereira (2010).

Kich et al. (2010) dizem que as universidades são organizações complexas devido às diversas correntes de pensamento que as integram, logo seu planejamento estratégico é considerado complexo e desafiador. Portanto, um planejamento estratégico padrão e engessado não funciona, é preciso que durante sua construção todos os envolvidos se sintam coautores do processo, para que ele gere resultado positivo.

Segundo Pereira (2010) apud Silva (2013), planejamento estratégico está relacionado com os objetivos de longo prazo e com as maneiras de alcançá-los, trata-se de questões que afetam a organização como um todo, é um processo político que envolve conflitos, poder e interesse, sua introdução enfrenta resistências, porque implica em mudanças, requer comprometimento de toda a organização, caso contrário não funcionará, além de ser um 
processo de adaptação da organização ao ambiente. Kunsch (2003, p. 214), corrobora com Ackoff (1978) e Gandin (1994) quando diz que o planejamento estratégico é pensado no longo prazo e o define como aquele que:

visa buscar as melhores formas para gerenciar as ações estratégicas das organizações, tendo por base as demandas sociais e competitivas, as ameaças e as oportunidades do ambiente, para que a tomada de decisões no presente traga os resultados mais eficazes possíveis no futuro.

As limitações mais comuns do processo para Pereira (2010), segundo Silva (2013), são a percepção do resultado negativo, o medo de mais trabalho, a necessidade de mudanças, a falta de comunicação do processo para os membros da organização, a incapacidade de alinhar a organização com o mundo, e a impressão de que os envolvidos estão sendo obrigados a mudar. Limitações ou desvantagens sempre serão observadas, devido à resistência interna, limitações de tempo e recursos, entre outras coisas, variando apenas a intensidade, que irá ditar a viabilidade ou não da implantação do planejamento estratégico.

Apesar de muitas Instituições de Ensino Superior confundirem, Kich et al (2010) dizem que planejamento estratégico e Plano de Desenvolvimento Institucional não são a mesma coisa. Inclusive podem ser conflitantes em algum momento, embora devam ser partes integradoras de um grande nome chamado Gestão da Universidade.

Segundo Otani, Helou e Michels (2011, p. 16):

as instituições concebidas a partir de um planejamento estratégico passaram a utilizar-se do Plano de Desenvolvimento Institucional para acompanhar seu desenvolvimento, tendo no PDI um instrumento operacional e pragmático. Enquanto outras instituições buscaram compreender o Plano como sendo o "planejamento estratégico" da instituição, sem um fundamento concreto para tal aspecto. [...] o PDI é um documento que, estruturado sob o broquel do Planejamento Estratégico surge para atender as determinações dos órgãos reguladores da educação superior, fato diretamente relacionado com a avaliação institucional. E se apresenta como sendo um documento de caráter pragmático e direcionado a um período temporal definido por decreto, consolidando a evolução institucional sob a orientação de eixos que atendem as demandas do Ministério da Educação. Já o Planejamento Estratégico é um processo complexo e reflexivo e que permite à instituição construir uma identidade pautada na compreensão de perspectivas. Neste sentido, pode-se afirmar que o Planejamento Estratégico constrói a identidade institucional por meio de um estudo baseado em perspectivas e de caráter prospectivo, estruturando contribuições no horizonte temporal determinado pelas Instituições. [...] Planejamento Estratégico estão fundamentadas em métodos participativos de discussão, as quais estão alinhadas com um referencial que vai além dos eixos propostos à construção do PDI, fazendo do documento um instrumento de gestão vinculado aos ensejos de um modelo gerencial maduro e atento as necessidades do contexto no qual as Instituições estão inseridas. 


\title{
CONTRIBUIÇÃO DO PLANO DE DESENVOLVIMENTO INSTITUCIONAL COMO FERRAMENTA DE \\ PLANEJAMENTO ESTRATÉGICO NA GESTÃO DE UMA INSTITUIÇÃO PRIVADA DE ENSINO \\ SUPERIOR DO RECIFE \\ DOI: http://dx.doi.org/10.5007/1983-4535.2014v7n3p77
}

Apesar do modelo de PDI proposto pelas legislações apresentadas pelo MEC não possuir um caráter estratégico e ter algumas limitações, Cardoso (2006) apud Silva (2013), conclui que o impacto do PDI sobre as IES é positivo, e quanto maior a cultura de planejamento e maior absorção pelos gestores dos conhecimentos sobre as técnicas de utilização dessa ferramenta, melhor estará a instituição, e por consequência, a educação superior brasileira.

Segundo Francisco et al (2012), “o PDI se configura como um documento estratégico da instituição". Dentro de suas principais funções, o documento elenca:

a. Missão,

b. Diretrizes de trabalho da instituição,

c. Consolidar a estrutura central das atividades acadêmicas desenvolvidas,

d.Determinar políticas em harmonia com os objetivos centrais da instituição e que se validam no processo de avaliação institucional.

Para os autores Francisco et al (2012, p.102, 103), o PDI tem uma importância na gestão institucional,

\begin{abstract}
destacando a relevância do bojo estrutural do documento, no sentido de posicionar as habilidades institucionais frente aos ensejos da conjuntura da educação superior. [...] o PDI consolida objetivos e metas que convergem para a consecução de objetivos comuns das instituições e dos órgãos reguladores da educação superior brasileira [...]o PDI passa a orientar uma percepção significativa da conjuntura da educação superior, permitindo que as instituições se posicionem frente aos desafios apontados pelas perspectivas, consolidando uma orientação significativa ao processo de avaliação institucional com base em uma concepção formativa. O documento se consolida como o principal referencial da avaliação externa das instituições a partir de sua articulação com as práticas gerenciais e de ensino preconizadas pelas instituições. Na contribuição ao processo gerencial, o PDI passa a inserir a instituição em um ambiente estratégico, tornando a elaboração do documento um processo sistêmico e dinâmico, que requer a participação de todos os membros da comunidade acadêmica. [...]o PDI passa a se consolidar como o instrumento norteador das políticas institucionais que convergem para à eficácia dos processos de ensino e aprendizagem, consolidando uma atividade sustentável perante aos ensejos das orientações regulatórias da educação superior brasileira.
\end{abstract}

Apesar das mudanças, as universidades não estão motivadas devido aos ruídos e demora na comunicação, além das propostas de mudança serem pouco atrativas, aparentemente (MORITZ, 2012). Porém, mudar é preciso neste período de transição de ideias, inversão de valores e futuro incerto. Logo, as práticas de estratégia e mudança nas universidades podem começar a partir de iniciativas e obrigatoriedades como o PDI que promove a avaliação do ambiente interno da universidade, ajuda a planejar e inovar para o 


\section{CONTRIBUICÃO DO PLANO DE DESENVOLVIMENTO INSTITUCIONAL COMO FERRAMENTA DE \\ PLANEJAMENTO ESTRATÉGICO NA GESTÃO DE UMA INSTITUIÇÃO PRIVADA DE ENSINO \\ SUPERIOR DO RECIFE \\ DOI: http://dx.doi.org/10.5007/1983-4535.2014v7n3p77}

futuro. Além disso, através do PDI as universidades devem compreender a importância do planejamento estratégico para a consecução de seus objetivos.

\section{METODOLOGIA}

Este estudo de caso, foi realizado após uma revisão da literatura que, de acordo com Merriam (2009), é relevante pois evita que o pesquisador ignore uma pesquisa a priori e repita algum estudo já realizado, entretanto não é um processo linear, logo o pesquisador pode retornar e revisar a literatura ao longo da pesquisa. As funções da revisão de literatura são: fundamentos para base do conhecimento, é o local onde a literatura é sintetizada e criticada, envolve combinações de temas e organização cronológica e situa o estudo.

A pesquisa seguiu orientação qualitativa que para Gephart (2004) é altamente descritiva. Dessa maneira, a descrição e o entendimento da atual interação humana, significados e processos que constituem ambientes organizacionais são de grande importância para a pesquisa qualitativa. Além disso, a pesquisa qualitativa pode fornecer bases para a compreensão de processos sociais que fundamentam a gestão. Como também, pode fornecer exemplos de questões de gestão e conceitos importantes que enriquecem o campo. Já Charmaz (2009) diz que a pesquisa qualitativa permite ao pesquisador seguir as indicações que vão surgindo durante a investigação do fenômeno estudado. Apesar dos métodos serem ferramentas, existem consequências, visto que na pesquisa qualitativa, a forma com que os dados são coletados afeta os fenômenos que serão vistos, como, onde e quando serão analisados, e qual sentido será produzido através deles. Por isso, é sugerido pela autora, deixar que o problema de pesquisa determine os métodos escolhidos.

A estratégia de investigação aqui utilizada será o estudo de caso, no qual, de acordo com Creswell (2010), o pesquisador explora profundamente um programa, um evento, uma atividade, um processo ou um ou mais indivíduos. De acordo com Stake (1995), um caso é específico e complexo, é um sistema limitado e integrado onde pessoas e programas são potenciais casos, ideia com a qual corrobora Merriam (2009) que define o estudo de caso como uma descrição e análise aprofundada de um sistema limitado. A estratégia foi escolhida por se apresentar mais coerente para a investigação da pergunta de pesquisa proposta.

Somam-se a estas características do estudo de caso a definição de Yin apud Merriam (2009) de que o estudo de caso consitui uma pesquisa empírica que investiga um fenômeno contemporâneo dentro do contexto da vida-real, especialmente quando a limitação e o 


\section{CONTRIBUICÃO DO PLANO DE DESENVOLVIMENTO INSTITUCIONAL COMO FERRAMENTA DE \\ PLANEJAMENTO ESTRATÉGICO NA GESTÃO DE UMA INSTITUIÇÃO PRIVADA DE ENSINO \\ SUPERIOR DO RECIFE \\ DOI: http://dx.doi.org/10.5007/1983-4535.2014v7n3p77}

contexto não são claramente evidentes. Quanto à seleção do objeto a ser pesquisado, Stake (1995) diz que deve-se selecionar casos típicos ou representativos que poderão maximizar o que se pode aprender e alerta que estudo de caso não é amostragem de pesquisa nem se estuda um caso para entender outros casos, a primeira obrigação é entender o caso escolhido, principalmente em se tratando de uma pesquisa qualitativa.

Para Merriam (2009) a seleção do caso é realizada após a decisão do que, onde, quando e quem observar e entrevistar. Neste estudo, a escolha foi por uma Faculdade particular na cidade do Recife por esta atender aos critérios estabelecidos na revisão de literatura quanto ao uso do PDI como ferramenta de planejamento estratégico na gestão da instituição. Quanto à tipologia deste estudo foi do tipo típica, que de acordo com Merriam (2009), reflete uma pessoa, situação ou um fenômeno de interesse. Outros parâmetros para a escolha do caso em questão foram a conveniência, devido às limitações de tempo e de recursos financeiros, a oportunidade de visita à instituição pelo pesquisador e o contato préexistente do pesquisador com o gestor e com o coordenador da instituição, que contribuiu para acesso aos dados.

A etapa inicial da pesquisa é caracterizada em sua abordagem pelo método indutivo no momento da coleta de dados inicial e decorrentes categorias preliminares, e das posteriores coletas e análise de mais dados subsequentes, conforme a orientação de Merriam (2009). Ao final do estudo, adota-se uma postura dedutiva, mais operacional na qual se está à procura de mais provas para apoiar o último conjunto de categorias como construção e contribuição do PDI. Neste período utilizou-se o critério de saturação, quando os dados coletado não acrescentam novas informações. Segundo Flick (2013), a saturação ocorre quando uma codificação adicional, não promove o enriquecimento das categorias, logo não proporciona novo conhecimento.

A coleta de dados foi feita através da entrevista formal e análise documental e usando o método observacional. Na coleta de dados busca-se obter dados relevantes, detalhados, focados e completos que revelam opiniões, sentimentos, intenções e as ações dos participantes, bem como os contextos e as estruturas de suas vidas (CHARMAZ, 2009, p.31). O estudo de caso observacional envolve entrevista formal ou informal, além da análise de documentos. Para realização da entrevista formal foi utilizado o gravador de áudio que segundo este mesmo autor, possibilita que o entrevistador dê atenção total ao seu participante de pesquisa com o contato visual constante, fornecendo dados detalhados. Quanto à análise 


\section{CONTRIBUICÃO DO PLANO DE DESENVOLVIMENTO INSTITUCIONAL COMO FERRAMENTA DE \\ PLANEJAMENTO ESTRATÉGICO NA GESTÃO DE UMA INSTITUIÇÃO PRIVADA DE ENSINO \\ SUPERIOR DO RECIFE \\ DOI: http://dx.doi.org/10.5007/1983-4535.2014v7n3p77}

documental foi realizada com textos existentes fornecidos pela instituição não manipulados pelo pesquisador até o momento da interpretação dos dados.

A primeira etapa analítica do estudo de caso foi a codificação, que "significa nomear segmentos de dados com uma classificação que, simultaneamente, categoriza, resume e representa cada parte dos dados" (CHARMAZ, 2009, p.69). Os códigos revelam a forma como selecionamos, separamos e classificamos os dados para iniciar uma avaliação analítica destes. Primeiramente foi realizada uma codificação, que "são provisórios, comparativos e fundamentados nos dados" (CHARMAZ, 2009, p.75). A codificação inicial permite o "surgimento de novas ideias", para isso sugere-se manter os "códigos curtos, simples, ativos e analíticos" (CHARMAZ, 2009, p. 74, 77).

Em seguida, foi realizada uma codificação focalizada, que significa "utilizar os códigos anteriores mais significativos e/ou frequentes para analisar minuciosamente grandes montantes de dados", através da qual pode-se "alternar entre entrevistas e as observações e comparar as experiências, ações e interpretações das pessoas". Além disso, "os códigos condensam os dados e proporcionam uma compreensão clara a respeito destes" (CHARMAZ, 2009 , p. 87,88$)$.

Esta pesquisa utilizou codificação, redação de memorandos, amostragem teórica na análise do resultado, conforme orientado por Charmaz (2009, p.166), visto que "ao dedicar-se à amostragem teórica, à saturação e à classificação, cria-se categorias sólidas e análises reveladoras".

\section{ANÁLISE DOS RESULTADOS}

A partir dos parâmetros legais do Decreto No. 5773 de 09/05/06, D.O.U de 10/05/06, que em seu Art. 16 apresenta os tópicos que devem constar no PDI das IES e que merecem atenção e avaliação do MEC/INEP, a Faculdade estruturou o seu Plano de Desenvolvimento Institucional 2011/2015 (PDI - 2011/2015).

A concepção do mencionado PDI veio através de uma sucessão de reuniões com o diretor geral, diretora administrativa - financeira, diretor acadêmico, coordenadores de cursos, uma representação dos professores, uma representação dos funcionários e uma representação dos alunos. Na Reunião Extraordinária do Conselho de Ensino e Extensão -CONSEPE no dia 02 de Dezembro de 2010, foi aprovado o PDI - 2011/2015. Após essa aprovação, o PDI foi 


\section{CONTRIBUICÃO DO PLANO DE DESENVOLVIMENTO INSTITUCIONAL COMO FERRAMENTA DE \\ PLANEJAMENTO ESTRATÉGICO NA GESTÃO DE UMA INSTITUIÇÃO PRIVADA DE ENSINO \\ SUPERIOR DO RECIFE \\ DOI: http://dx.doi.org/10.5007/1983-4535.2014v7n3p77}

enviado à Mantenedora para aprovação final e na sequência foi encaminhado ao MEC e finalmente iniciado o processo de sua implementação.

Segundo o X (2013), gestor responsável pela elaboração e implantação do PDI na instituição, o PDI adotado foi fruto de 1 (um) ano de reuniões e continua em constantes ajustes, a instituição prevê uma modificação em 2015, conforme sugerido por Kich et al. (2010), quando diz que para que a construção do planejamento estratégico em universidades faça com que as pessoas da instituição sintam-se coautoras do processo, deve ser discutida diversas vezes para que gerar resultado positivo.

O que motivou a instituição foi a exigência do Ministério de Educação e Cultura, entretanto $\mathrm{X}$ acredita que o modelo apresentado pela instituição já traz a conversão que leva ao planejamento estratégico. Logo, foi preciso apenas adaptar a parte formal exigida pelo MEC ao planejamento estratégico de modo decisivo. Tanto que $X$ ressalta a presença do planejamento estratégico no PDI atual quando compara o presente com o anterior também no formato exigido pelo Ministério, mas sem as ferramentas do planejamento estratégico.

Ao contrário do que defende Kich et al (2010), quando afirmam que planejamento estratégico e Plano de Desenvolvimento Institucional não são a mesma coisa. E a LDB (BRASIL, 1996), a Lei do SINAES (BRASIL, 2004), o decreto presidencial que regulamenta o SINAES (BRASIL, 2006) e a própria orientação do MEC (BRASIL, 2007) para a elaboração do PDI que não fazem referências à estratégia ou planejamento estratégico.

Por outro lado, as colocações de X corroboram com os estudos de Rissi et al (2009) quando afirmam que o planejamento estratégico das universidades é o Plano de Desenvolvimento Institucional. E com o estudo de Francisco et al (2012), quando afirma que "o PDI se configura como um documento estratégico da instituição". Além disso "o PDI passa a inserir a instituição em um ambiente estratégico, tornando a elaboração do documento um processo sistêmico e dinâmico, que requer a participação de todos os membros da comunidade acadêmica" (2012, p.103).

Segundo X, o PDI é utilizado por força do Ministério da Educação, logo a instituição precisa implementar devido às visitas dos avaliadores que checam se todos os itens estão sendo cumpridos. Por isso, a instituição faz constantes leituras e análises para avaliar se os planos estão no caminho certo, se está se fazendo o que é necessário, se é preciso fazer reparações no plano. 


\section{CONTRIBUICÃO DO PLANO DE DESENVOLVIMENTO INSTITUCIONAL COMO FERRAMENTA DE \\ PLANEJAMENTO ESTRATÉGICO NA GESTÃO DE UMA INSTITUIÇÃO PRIVADA DE ENSINO \\ SUPERIOR DO RECIFE \\ DOI: http://dx.doi.org/10.5007/1983-4535.2014v7n3p77}

O quadro 1 (Anexo A), apresenta os requisitos mínimos estabelecidos no decreto presidencial que é composto por dez eixos temáticos e os tópicos encontrados no PDI da Faculdade. O MEC permite que a construção do PDI utilize os dez eixos temáticos de forma livre, garantindo às instituições o exercício de suas criatividades e liberdades no processo de sua elaboração (MEC, 2007). Apesar disso, os pontos cumprem as exigências do Ministério. Ademais, ratifica o estudo de Francisco et al (2012), quando elenca o que o documento apresente, dentre as suas principais funções, a missão, diretrizes de trabalho da instituição, consolidação da estrutura central das atividades acadêmicas desenvolvidas e determine políticas em harmonia com os objetivos centrais da instituição que se validam no processo de avaliação institucional. Isto para que o PDI se configure como documento estratégico da instituição.

Para implementar os pontos contidos no PDI, a instituição sofreu resistência, principalmente dos funcionários que ficaram desconfortáveis com as mudanças requeridas pelo plano. Esta atitude confirmando o que Pereira (2010) apud Silva (2013) expressa sobre o planejamento estratégico ser um processo político e sua introdução enfrenta resistências por implicar em mudanças e, assim, requerer comprometimento de toda a organização, caso contrário corre o risco de não funcionar.

Apesar disso, de um modo geral $\mathrm{X}$ apontou que o plano como ferramenta de planejamento estratégico contribuiu de modo positivo com a comunicação interna na instituição que era algo desejado por todos os membros da organização.

Logo, pode-se afirmar que o plano de desenvolvimento institucional como ferramenta de planejamento estratégico contribuiu com a gestão da instituição privada de ensino superior do Recife corroborando com a conclusão de Cardoso (2006) apud Silva (2013), sobre o impacto do PDI sobre as IES ser positivo, e quanto maior a cultura de planejamento, maior absorção pelos gestores dos conhecimentos sobre as técnicas de utilização dessa ferramenta, melhor estará a instituição, e por consequência, a educação superior brasileira.

\section{CONCLUSÃO}

O presente trabalho teve como objetivo analisar a contribuição do plano de desenvolvimento institucional como ferramenta de planejamento estratégico na gestão da instituição privada de ensino superior do Recife. 
Para isso foi realizado uma pesquisa qualitativa e a estratégia adotada foi estudo de caso. Para coleta de dados foi realizado entrevista e análise documental. A análise dos dados foi feita através de codificação, redação de memorando e amostragem teórica visando uma criar categorias sólidas e análises reveladoras através da saturação e classificação.

Os achados deste estudo corrobora com outros estudos realizados sobre plano de desenvolvimento institucional e planejamento estratégico em universidades. Além disso, foi observado que a instituição utilizou o PDI como ferramenta estratégica apesar do PDI não fazer menção ou ter este objetivo inicial. A instituição enfrentou a resistência por parte dos funcionários na implantação do plano, contudo o saldo do PDI como ferramenta de planejamento estratégico resultou em diversos benefícios para a instituição, ou seja, contribuiu com a gestão na busca pela melhoria da instituição e consequentemente com o ensino superior privado.

\section{REFERÊNCIAS}

ACKOFF, R. L. A Natureza e o Conteúdo do Planejamento. In: Planejamento Empresarial. Rio de Janeiro: LTC, 1978. BRASIL. Ministério da Educação. Instruções para elaboração de Plano de Desenvolvimento Institucional. Brasília, DF, 2007. Disponível em: <http://www2.mec.gov.br/sapiens/pdi.html>. Acesso em: 05 nov. 2013.

CHARMAZ, Kathy. A construção da teoria fundamentada: guia prático para análise qualitativa. Porto Alegre: Artmed, 2009.

CRESWELL, John W. Projeto de pesquisa: métodos qualitativo, quantitativo e misto. 3ed. Porto Alegre: Artmed, 2010.

FLICK, Uwe. Introdução à metodologia de pesquisa: um guia para iniciantes. Porto Alegre: Penso, 2013.

FRANCISCO, Thiago Henrique Almino; NAKAYAMA, Marina Keiko; RAMOS, Alexandre Moraes; OLIVEIRA, Paulo Cristiano. A contribuição do PDI nas atividades de planejamento e gestão das instituições de educação superior. Revista GUAL, v. 5, n. 3, p. 81-107, dez.. Florianópolis, 2012.

GANDIN, Danilo. A Prática do Planejamento Participativo: na educação e em outras instituições, grupos e movimentos dos campos cultural, social, político, religioso e governamental. Petrópolis, RJ: Vozes, 1994.

GEPHART,R. Qualitative research and the Academy of Management Journal. Academy of Management Journal, v. 47, n. 4, p. 454-462, 2004. 
INEP, Instituto Nacional de Estudos e Pesquisas Educacionais Anísio Teixeira. Sinopses Estatísticas da Educação Superior - Graduação. Brasil,2013. Disponível em:

<http://portal.inep.gov.br/superior-censosuperior-sinopse>. Acesso em: 05 de nov. 2013.

KICH, Juliane Ines Di Francesco; PEREIRA, Maurício Fernandes; ALMEIDA, Martinho Isnard Ribeiro de; MORITZ, Gilberto de Oliveira. Planejamento estratégico em universidades. X Coloquio Internacional sobre Gestión Universitaria en América del Sur. Mar del Plata, 2010.

KUNSCH, Margarida M. K. Planejamento de relações públicas na comunicação integrada. 3 ed. São Paulo: Summus, 2003.

MERRIAM, S. Designing your study and selecting a sample. In: Qualitative research: a guide to design and implementation. San Francisco: Jossey-Bass, 2009. Cap.4

MORITZ, Mariana Oliveira; MORITZ, Gilberto de Oliveira; MELO, Michelle Bianchini de; SILVA, Flora Moritz da. A implantação do planejamento estratégico em organizações complexas: o caso da universidade do estado de Santa Catarina. Revista GUAL, v. 5, n. 1, pp. 228-249, jan./fev./mar./abr. Florianópolis, 2012.

OTANI, Nilo; HELOU, Angela Regina Heinzen Amin; MICHELS, Expedito. Diferenças entre o PDI e o planejamento estratégico na percepção dos PIs de IES do segmento privado não universitário. XI Colóquio Internacional sobre Gestão Universitária na América do Sul. Florianópolis, 2011.

RISSI, Maurício; BATISTA, Rodrigo Antonio de Oliveira; PACHECO, Anderson Sasaki Vasques; FREIRE, Patricia De Sá, SOARES, Aline Pereira; PACHECO, Andressa Sasaki Vasques. Plano de Desenvolvimento Institucional da UFSC: um olhar do corpo discente. IX Colóquio Internacional sobre Gestão Universitária na América do Sul. Florianópolis, 2009.

SILVA, Júlio Eduardo Ornelas. Contribuições do Plano de Desenvolvimento Institucional e do planejamento estratégico na gestão de universidades federais brasileiras. Dissertação submetida ao Programa de Pós-Graduação em Administração da Universidade Federal de Santa Catarina, para a obtenção do Grau de Mestre em Administração. Florianópolis, 2013.

STAKE,R. The art of case study research. Thousand Oaks: Sage, 1995. 
ANEXO A

\begin{tabular}{|c|c|}
\hline $\begin{array}{l}\text { PDI - Requisitos Mínimos } \\
\text { (BRASIL, 2007) }\end{array}$ & PDI- Faculdade \\
\hline \multirow{13}{*}{ Perfil institucional; } & Perfil Institucional \\
\hline & Histórico de Implantação e Desenvolvimento da Instituição \\
\hline & Missão, Princípios, Visão e Valores e objetivos \\
\hline & Missão \\
\hline & Princípios \\
\hline & Visão \\
\hline & Metas da Instituição \\
\hline & Áreas de Atuação Acadêmica \\
\hline & Objetivos e Metas da Instituição \\
\hline & Objetivo Geral \\
\hline & Objetivos Específicos \\
\hline & Metas da Instituição \\
\hline & Áreas de atuação acadêmica \\
\hline \multirow{10}{*}{ Projeto Pedagógico Institucional } & Projeto Pedagógico Institucional \\
\hline & Inserção regional \\
\hline & $\begin{array}{l}\text { Princípios Filosóficos e Técnico-Metodológicos Gerais que } \\
\text { Norteiam As Práticas Acadêmicas da Instituição }\end{array}$ \\
\hline & $\begin{array}{lllllll}\begin{array}{l}\text { Política de ensino e extensão, de gestão } \\
\text { responsabilidade social }\end{array} & \text { e de } \\
\end{array}$ \\
\hline & Políticas de Ensino \\
\hline & Políticas de Extensão \\
\hline & Responsabilidade Social da IES \\
\hline & Oportunidades diferenciadas de integralização curricular \\
\hline & Iluminação \\
\hline & Iluminação da Faculdade \\
\hline \multirow{11}{*}{$\begin{array}{c}\text { Cronograma de implantação e } \\
\text { desenvolvimento da instituição e } \\
\text { dos cursos (presencial e a } \\
\text { distância); }\end{array}$} & Implementação da instituição e organização acadêmica \\
\hline & $\begin{array}{l}\text { Cronograma de implantação e desenvolvimento da } \\
\text { instituição para o período de vigência do PDI }\end{array}$ \\
\hline & $\begin{array}{l}\text { Projeção de Cursos de Graduação Modalidade Presencial } \\
(2011-2015) \text { - Curto prazo }\end{array}$ \\
\hline & Projeção de Cursos de Pós Graduação \\
\hline & Projeção de Cursos de Extensão \\
\hline & Plano para atender às diretrizes pedagógicas \\
\hline & Perfil do Egresso \\
\hline & Seleção de conteúdos \\
\hline & Processo de Avaliação \\
\hline & Atividade prática profissional, complementares e de estágios \\
\hline & $\begin{array}{l}\text { Inovações consideradas significativas, especialmente quanto } \\
\text { à flexibilidade dos componentes curriculares }\end{array}$ \\
\hline \multirow{4}{*}{ Perfil do corpo docente; } & Corpo Docente \\
\hline & Quadro Do Corpo Docente \\
\hline & Requisitos De Titulação \\
\hline & Regime De Trabalho \\
\hline \multirow{6}{*}{$\begin{array}{l}\text { Organização administrativa da } \\
\text { IES; }\end{array}$} & Corpo Técnico-Administrativo \\
\hline & Os critérios de seleção e contratação \\
\hline & $\begin{array}{l}\text { Políticas de qualificação, plano de carreira e regime de } \\
\text { trabalho }\end{array}$ \\
\hline & Corpo técnico-administrativo \\
\hline & Organização administrativa \\
\hline & Estrutura organizacional e as instâncias de decisão \\
\hline
\end{tabular}




\begin{tabular}{|c|c|}
\hline & Organograma institucional e acadêmico \\
\hline & Órgãos colegiados: competências e composição \\
\hline & Órgãos de apoio às atividades acadêmicas \\
\hline & Autonomia das IES em relação à mantenedora \\
\hline \multirow{8}{*}{$\begin{array}{l}\text { Políticas de atendimento aos } \\
\text { discentes; }\end{array}$} & Corpo discente \\
\hline & Formas de acesso \\
\hline & Programas de apoio \\
\hline & Pedagógico e financeiro \\
\hline & Estímulos à permanência \\
\hline & Organização estudantil \\
\hline & Acompanhamento dos egressos \\
\hline & Evolução do número de aluno \\
\hline \multirow{4}{*}{$\begin{array}{l}\text { Avaliação e acompanhamento do } \\
\text { desenvolvimento institucional; }\end{array}$} & Auto avaliação institucional \\
\hline & $\begin{array}{l}\text { Metodologia, dimensões e instrumentos a serem utilizados } \\
\text { no processo de auto avaliação }\end{array}$ \\
\hline & $\begin{array}{l}\text { Formas de participação da comunidade acadêmica, técnica e } \\
\text { administrativa, incluindo a atuação da comissão própria de } \\
\text { avaliação - CPA, em conformidade com o sistema nacional } \\
\text { de avaliação da educação superior - SINAES. }\end{array}$ \\
\hline & Formas de utilização dos resultados das avaliações \\
\hline \multirow{14}{*}{ Infraestrutura; } & Infraestrutura Acadêmica \\
\hline & Infraestrutura física e instalações acadêmicas \\
\hline & $\begin{array}{l}\text { Tipologia e quantidade de ambientes/laboratórios de acordo } \\
\text { com a proposta do curso }\end{array}$ \\
\hline & Salas de Aula \\
\hline & $\begin{array}{lcccc}\text { Salas das } & \text { Coordenações, } & \text { Professores, Reuniões } & \text { e } \\
\text { Orientações } & & & \\
\end{array}$ \\
\hline & Laboratórios de Informática \\
\hline & $\begin{array}{l}\text { Acesso a equipamentos de Informática pelos Docentes e } \\
\text { Discentes }\end{array}$ \\
\hline & Auditório / Teatro \\
\hline & Salas de Vídeo \\
\hline & Biblioteca \\
\hline & Equipamentos \\
\hline & Recursos Audiovisuais \\
\hline & Instalações e Lazer \\
\hline & Estacionamento \\
\hline & $\begin{array}{l}\text { Atendimento às pessoas portadoras de necessidades } \\
\text { educacionais especiais ou com mobilidade reduzida }\end{array}$ \\
\hline & $\begin{array}{l}\text { Plano de atendimento aos portadores de necessidades } \\
\text { educacionais especiais }\end{array}$ \\
\hline $\begin{array}{c}\text { Aspectos financeiros e } \\
\text { orçamentários; }\end{array}$ & Demonstrativo de capacidade e sustentabilidade financeira \\
\hline $\begin{array}{l}\text { Anexos, que deve conter o } \\
\text { regimento ou estatuto da IES. }\end{array}$ & \\
\hline
\end{tabular}

Quadro 1 Requisitos para PDI estabelecidos pelo decreto presidencial e PDI da Faculdade Elaborado pelos autores (2013) 